\title{
Successful capture of Toxocara canis larva antigens from human serum samples
}

\author{
Aarón Rodríguez-Caballero ${ }^{1}$, Mario Noé Martínez-Gordillo ${ }^{1}$, Yolanda Medina-Flores ${ }^{2}$, María Edith Medina-Escutia ${ }^{2}$, \\ Antonio Meza-Lucas ${ }^{3}$, Dolores Correa ${ }^{4}$, Silvia Caballero-Salazar ${ }^{1}$ and Martha Ponce-Macotela ${ }^{1 *}$
}

\begin{abstract}
Background: Toxocara canis is a nematode that parasitizes dogs, while humans are paratenic hosts. When humans are infected the migrating larvae damage the liver, lungs and even the nervous system. Larva migrans diagnosis is based on immunological techniques; however, the commercial immunodiagnostic kits detect anti-T. canis antibodies which may cross-react with other parasites, mainly nematodes with extra-intestinal migration. Moreover, antibodies do not necessarily reflect an active infection; so detection and quantification of circulating antigens may provide appropriate and timely information for treatment, which prevents irreversible damage. Here we report the standardization of a monoclonal antibody based antigen capture ELISA to diagnose human toxocariasis without cross-reaction.
\end{abstract}

Methods: We developed anti-T. canis polyclonal antibodies in rabbits and a monoclonal antibody in mouse which did not cross-react with 15 antigens from several parasites. The sandwich ELISA standardization was performed using sera from mice experimentally infected. We tested the method using 29 positive and 58 negative human sera previously typified with a commercial kit, which detects antibodies.

Results: Only $5.0 \mu \mathrm{g} / \mathrm{mL}$ and $10 \mu \mathrm{g} / \mathrm{mL}$ polyclonal antibodies and monoclonal antibody, respectively, were needed in the sandwich ELISA standardization, detecting since $440 \mathrm{pg} / \mathrm{mL}$ larva antigens. Nine out of 29 antibody-positive sera were also positive for antigens and no false positive were found. Taking the antibody kit as the reference standard, the sensibility and specificity of the antigen test were $31 \%$ and $100 \%$, respectively.

Conclusions: With these tools we established a detection threshold as low as $440 \mathrm{pg} / \mathrm{mL}$ antigen. Monoclonal antibody is specific, and did not cross-react with antigens from other parasites. Detection of circulating antigens helps provide appropriate and timely treatment and prevents irreversible damage.

Keywords: Toxocara canis, Larva migrans, Antigen capture

\section{Background}

The migration of Toxocara canis larvae is injurious to human beings, because they invade the liver, the lungs or the nervous system [1]. Dogs are definitive hosts, and the parasite successfully infects puppies by uterine, trans-mammary or environmental routes, with prevalence near $100 \%$ in some places [2]. In contrast, $12-21 \%$ of adult dogs are infected with the parasite [3]. As Toxocara females shed an average of 68,000 eggs/day, dogs are an important source of environmental contamination $[4,5]$. Children are most

\footnotetext{
* Correspondence: macotelam@yahoo.com

'Laboratorio de Parasitología Experimental, Instituto Nacional de Pediatría, Insurgentes Sur No. 3700-C, Colonia Insurgentes Cuicuilco. Delegación Coyoacan, México D.F 04530, México

Full list of author information is available at the end of the article
}

susceptible to infection with Toxocara embryonated eggs due to their playing behavior and their tendency to eat dirt. Humans serve as paratenic hosts and the migrating parasite produces: visceral larva migrans (VLM) characterized by hepatic damage and Löffler syndrome with fever, pulmonary inflammatory infiltrate and eosinophilia [6]; ocular larva migrans (OLM) which in severe cases leads to eyesight loss [7]; eosinophilic meningo-encephalitis (EME) [8]; and covert toxocariasis (CT) [9]. Currently, larva migrans is diagnosed by immunological methods, which detect antibodies against excretion-secretion antigens [10]. However, this method has limitations, i.e. there is cross-reactivity with antigens from other parasites [10-12]. For treatment purposes it is important to know if there are circulating 
antigens. There have been few reports that show the capture of $T$. canis larvae excretion and secretion antigens $\left(\mathrm{L}_{2} \mathrm{TES}\right)$ as an alternative diagnostic strategy, but with variable results [13-15]. Here, we report the standardization of an ELISA to capture and quantify circulating Toxocara antigens to diagnostic human toxocariasis without crossreaction.

\section{Methods}

\section{Ethical approval}

Protocol was approved by the research and ethic committees of National Institute of Pediatrics. All animal procedures were performed in accordance with the guidelines of the Coordinator Commission of the National Institutes of Health of Mexico (Institutos Nacionales de Salud, NOM062-ZOO-1999).

\section{Toxocara canis larvae}

T. canis adults were obtained from the small intestines of puppies euthanized at the Canine Control Centre in Tlalpan, México D.F., as described elsewhere [3]. Parasite females were isolated with a paintbrush or forceps, washed with PBS pH 7.2 and processed for culture in the SGHP medium (Saline, Glucose, Human Plasma) described previously [4]. Toxocara eggs were harvested, concentrated by centrifugation, and incubated for one month until larvae developed, which were induced to hatch following the physiological method described elsewhere [16]. Larvae were purified with Lymphoprep and maintained in RPMI-1640 medium, to collect excretionsecretion antigens $\left(\mathrm{L}_{2} \mathrm{TES}\right)$ in a tube containing protease inhibitors cocktail (Sigma Aldrich, USA); subsequently they were concentrated by centrifugation in Amicon columns (10 KDa cutoff), quantified by the Bradford method, aliquoted and stored at $-70^{\circ} \mathrm{C}$ until use [17].

\section{Monoclonal antibody (MoAb) production}

Five female BALB/c mice were intraperitoneally inoculated with 500 live Toxocara larvae. Every two weeks a blood sample was collected from the tail vein; the sera were used to evaluate the immune response. Thirty days later, one mouse was euthanized, its spleen was isolated and the cells were fused with the mouse myeloma line X63Ag8.653 at a 5:1 ratio. Hybrid cells were selected following the standard method [18]. Chimeric cells secreting antibodies against $T$. canis larvae were selected. The cross-reactivity was tested using both excretionsecretion and somatic antigens of $T$. canis adult. Also Toxocara cati, Ascaris suum, Trichinella spiralis, Ancylostoma caninum, Dipylidium caninum, Fasciola hepatica, Leishmania mexicana, Trypanosoma cruzi, Giardia intestinalis, Trichomonas vaginalis and Acanthamoeba spp. antigens were tested. The controls were hyperimmune and preimmune sera from experimentally infected mouse. One
MoAb (termed INP-1E4G4C2) was selected and cloned twice by limiting dilution [19]. The resultant antibody was purified using Montage Antibody Purification Kit with Prosep ${ }^{\circ}$-G (Millipore, USA), typed [20] quantified and stored at $-20^{\circ} \mathrm{C}$ until use.

\section{Polyclonal antibodies (PoAb) production}

Two New Zealand rabbits were intraperitoneally injected with five thousand T. canis live larvae. To detect antibody increase, blood samples were obtained from the ear vein weekly. The rabbits were anesthetized and euthanized by bleeding when the titer was1:64,000. Serum was harvested and the IgG fraction was isolated with the Montage Antibody Purification Kit with Prosep ${ }^{\circ}$-G (Millipore, USA), following the manufacturer's instructions. The protein concentration was determined, and the antibodies were divided into aliquots and stored at $-20^{\circ} \mathrm{C}$ until use.

\section{Determination of the optimal MoAb concentration for ELISA}

ELISA plates Immulon 2HB (Dynatech, USA) was coated with $100 \mu \mathrm{L} /$ well of 0.0 to $40 \mu \mathrm{g} / \mathrm{mL}$ MoAb in borate buffer and incubated overnight at $4^{\circ} \mathrm{C}$. The plates were then washed three times and non-specific binding sites were blocked with $1 \%$ skimmed milk in PBS-Tween 20 $(0.05 \%)$ for $30 \mathrm{~min}$ at $37^{\circ} \mathrm{C}$ and then rinsed with $0.9 \% \mathrm{NaCl}-0.05 \% \mathrm{Tween} 20$. An anti-mouse IgG-HRP conjugate (Sigma, A4416) was added at a 1:8,000 dilution in PBS-Tween 20, incubated for $2 \mathrm{~h}$ at $37^{\circ} \mathrm{C}$ and washed three times with $0.9 \% \mathrm{NaCl}-0.05 \%$ Tween 20 . The reaction was revealed with chromogen/substrate solution $(0.05 \mathrm{M}$ citrate/citric acid, 0.04 mg O-phenylenediamine and 0.12\% $\mathrm{H}_{2} \mathrm{O}_{2}$ ). The reaction was stopped with $\mathrm{H}_{2} \mathrm{SO}_{4}$ and the absorbance was measured at $490 \mathrm{~nm}$ on an automatic ELISA reader Teca (Sunrise, Switzerland). The MoAb optimal concentration for the ELISA was $10.0 \mu \mathrm{g} / \mathrm{mL}$ (Figure 1).

\section{Sandwich ELISA standardization for $\mathrm{L}_{2}$ TES detection}

The $\mathrm{L}_{2}$ TES capture was performed as follows: polystyrene wells were coated overnight at $4^{\circ} \mathrm{C}$ with $0.1,1.0,5.0$, 10.0 and $25 \mu \mathrm{g} / \mathrm{mL}$ of PoAb in borate buffer $(100 \mathrm{mM}$ boric acid, $0.025 \mathrm{M}$ sodium tetraborate, $75 \mathrm{mM}$, sodium chloride) $\mathrm{pH}$ 8. Unspecific sites were blocked for one hour at room temperature with $1 \%$ skimmed milk in PBS-Tween $20 . \mathrm{L}_{2}$ TES were added at 0.0 , and tenfold increment from 0.0001 , until $10 \mu \mathrm{g} / \mathrm{mL}$ and incubated at $37^{\circ} \mathrm{C}$ for $2 \mathrm{~h}$. Afterwards $10 \mu \mathrm{g} / \mathrm{mL}$ of the MoAb were added and incubated at room temperature. The antimouse IgG-HRP $(1: 8,000)$ was aggregated and incubated as described before. In every step, the plate was washed three times with $\mathrm{NaCl}$-Tween 20 . 


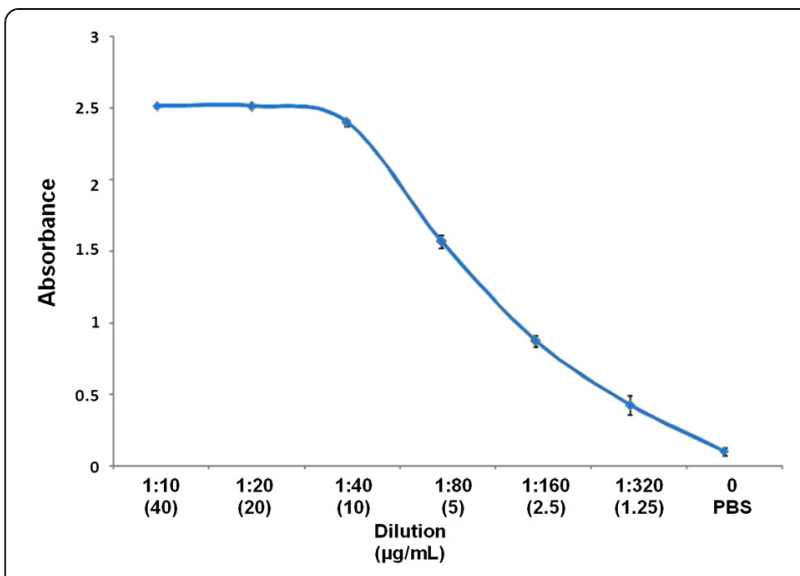

Figure 1 Determination of the optimal 1E4G4C2 MoAb concentration for the ELISA. 96-well polystyrene plate was coated with 0.0, 1.0, 2.5, 5.0, 10, 20 and $40 \mu \mathrm{g} / \mathrm{mL}$ of MoAb; non-specific binding sites were blocked with 1\% skimmed milk; anti-mouse lgG-HRP conjugate was added at a 1:8,000 dilution and the reaction was revealed with chromogen/substrate solution. The results are shown as the arithmetic media \pm standard deviation from three triplicate assays.

\section{Detection of $L_{2}$ TES in human sera}

We tested the method using 29 positive and 58 negative serum samples previously tested with a commercial kit (Sciemedx, USA) which detects antibodies against T. canis larvae antigens. A fraction of each sample was treated with EDTA to dissociate immune complexes; briefly, samples were diluted 1:1 with 1.0 M EDTA, pH 7.5, boiled for 10 minutes and centrifuged at 12,000 x g/5 minutes, and the supernatant was used in the test [21]. Another serum fraction was used diluted with PBS instead of EDTA.
ELISA was performed with the PoAb at $5 \mu \mathrm{g} / \mathrm{mL}, 100 \mu \mathrm{L}$ of sera with or without treatment with EDTA, the MoAb at $10 \mu \mathrm{g} / \mathrm{mL}$ and anti-mouse IgG-HRP diluted 1:8,000.

In all cases, the cut-off value was obtained adding three times the standard deviation to the mean absorbance value of the negative samples. The experiments were repeated three times.

\section{Western blot}

Electrophoresis was performed in a Mini-Protean II (BioRad, USA) on 4-20\% polyacrylamide slab gradient gels (BioRad,USA), with Kaleidoscope prestained standards (BioRad,USA) and $100 \mu \mathrm{g} \mathrm{L} 2 \mathrm{TES} /$ well; electrophoresis was at $150 \mathrm{~V}$ for $2 \mathrm{~h}$. Proteins were transferred to a PVDF membrane Immobilon (Millipore, USA) at $60 \mathrm{~V}$ for $1.5 \mathrm{~h}$ in Mini Trans-Blot (BioRad, USA). Nonspecific sites were blocked overnight with 5\% skimmed milk in PBS-Tween 20 at $4^{\circ} \mathrm{C}$. The blot was then incubated $2 \mathrm{~h}$ with INP1E4G4C2 MoAb at room temperature and washed with PBS-Tween 20 (0.05\%). The anti-mouse IgG-HRP conjugate, diluted 1:1,000 was then added and incubated for $2 \mathrm{~h}$ at room temperature. After three washes with PBS-Tween 20 (0.05\%) and two with PBS, the substrate/ chromogen solution (30 mg 3,3'-Diaminobenzidine, and $6 \mu \mathrm{L} \mathrm{30 \%} \mathrm{H}_{2} \mathrm{O}_{2}$ in $60 \mathrm{~mL}$ PBS) was added and the reaction was stopped with distilled water.

\section{Results}

The INP-1E4G4C2 is an IgG1 isotype MoAb that did not show cross-reactivity with other parasite antigens tested, including somatic antigens from $T$. canis adults.

Table 1 Detection of cross-reactions of INP-1E4G4C2 MoAb against antigens from several parasites

\begin{tabular}{llll}
\hline & Absorbance at 490 nm & & Preimmune serum \\
\cline { 2 - 4 } Antigens & INP-1E4G4C2 MoAb & Hyperimmune serum & 0.116 \\
\hline Toxocara canis L $_{2}$ TES & 2.5 & 2.5 & 0.137 \\
Toxocara canis larvae somatic antigen & 2.5 & 2.5 & 0.146 \\
Toxocara canis ATES & 0.27 & 2.5 & 0.204 \\
Toxocara canis adult somatic antigen & 0.287 & 1.842 & 0.085 \\
Toxocara cati & 0.201 & 1.089 & 0.099 \\
Ascaris suum & 0.285 & 0.825 & 0.12 \\
Ancylostoma caninum & 0.226 & 1.132 & 0.042 \\
Trichinella spiralis & 0.26 & 0.898 & 0.141 \\
Fasciola hepatica & 0.139 & 0.388 & 0.116 \\
Dipilidium caninum & 0.147 & 0.269 & 0.191 \\
Giardia intestinalis & 0.138 & 0.301 & 0.107 \\
Trypanosoma cruzi & 0.131 & 0.292 & 0.12 \\
Leishmania spp & 0.089 & 0.218 & 0.129 \\
Trichomonas vaginalis & 0.091 & 0.163 & 0.149 \\
Acantamoeba spp & 0.135 & 0.296 &
\end{tabular}

Cut-off: 0.35; $\mathrm{L}_{2}$ TES: Larvae 2 Toxocara excretion-secretion antigens. ATES: Secretion excretion antigens from Toxocara canis adult. 


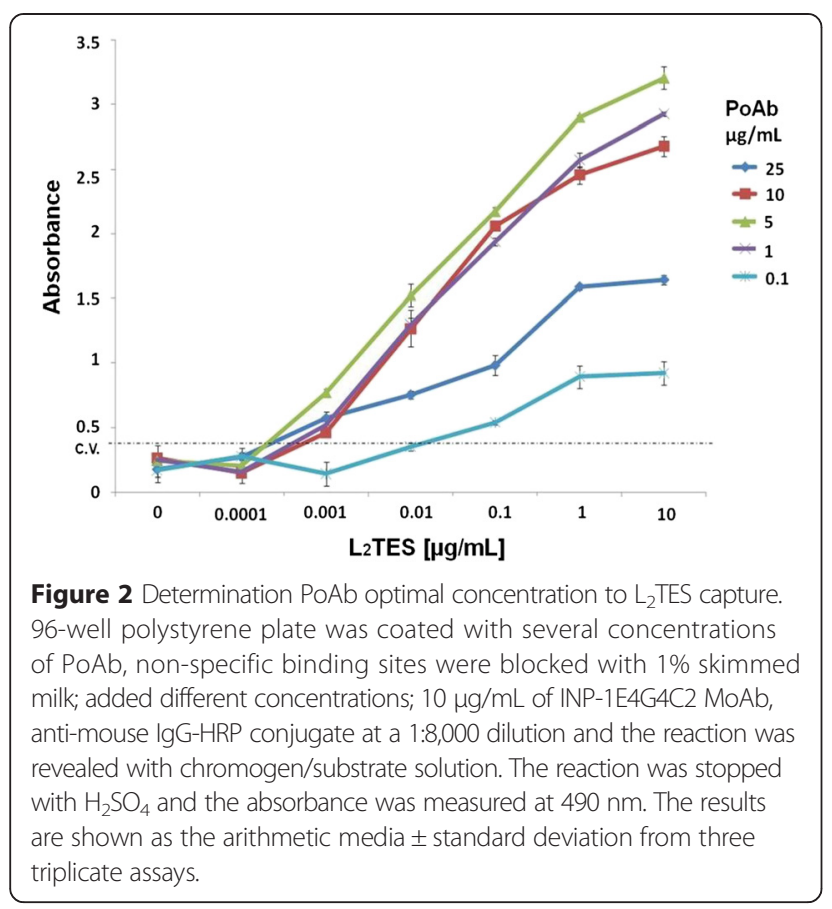

Only $\mathrm{L}_{2} \mathrm{TES}$ and larval somatic antigen gave high absorbance values; in contrast, the hyperimmune mouse serum recognized several parasites (Table 1). MoAb optimal concentration was $10 \mu \mathrm{g} / \mathrm{mL}$ because the absorbance inflection point was at $5.0 \mu \mathrm{g} / \mathrm{mL}$ (Figure 1). Sandwich ELISA standardization was with $5.0 \mu \mathrm{g} / \mathrm{mL}$ and $10 \mu \mathrm{g} / \mathrm{mL}$ of the

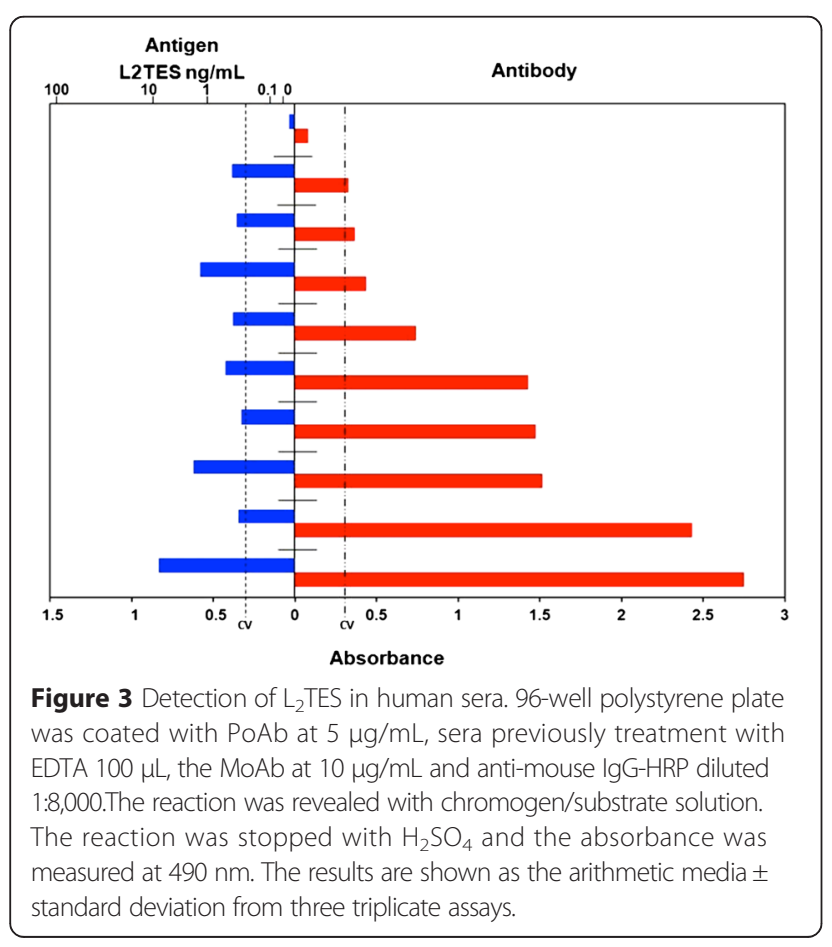

polyclonal and monoclonal antibodies, and was detected since $440 \mathrm{pg} / \mathrm{mL}$ of $\mathrm{L}_{2} \mathrm{TES}$ (Figure 2).

With this technique we found from $470 \mathrm{pg} / \mathrm{mL}$ to $10 \mathrm{ng} /$ $\mathrm{mL}$ of antigen in 9 out of 29 (sensitivity $=31 \%$ ) positive sera previously diagnosed with a commercial kit that detects antibodies. In none of the 58 negative samples the antigen was detected (specificity $=100 \%$ ) (Figure 3 ). We were able to detect antigens only in samples treated with EDTA.

The western blot revealed that INP-1E4G4C2 MoAb recognized three bands of 130, 205 and $>205 \mathrm{KDa}$, respectively (Figure 4).

\section{Discussion}

Toxocara larva migrans diagnosis is not easy, because the methods are based on the detection of antibodies against the parasite, which do not determine the infection status and may give rise to false positive results, due to crossreactions with other parasites, especially nematodes. With the intention to develop a technique for $\mathrm{L}_{2}$ T.canis circulating antigens detection, we obtained one monoclonal antibody against $\mathrm{L}_{2} T$. canis antigens; which neither identified $T$. canis adult excretion-secretion and somatic antigens, nor presented cross-reactivity with other nematodes such as: T. cati, A. suum, A. caninum or T. spiralis (Table 1).

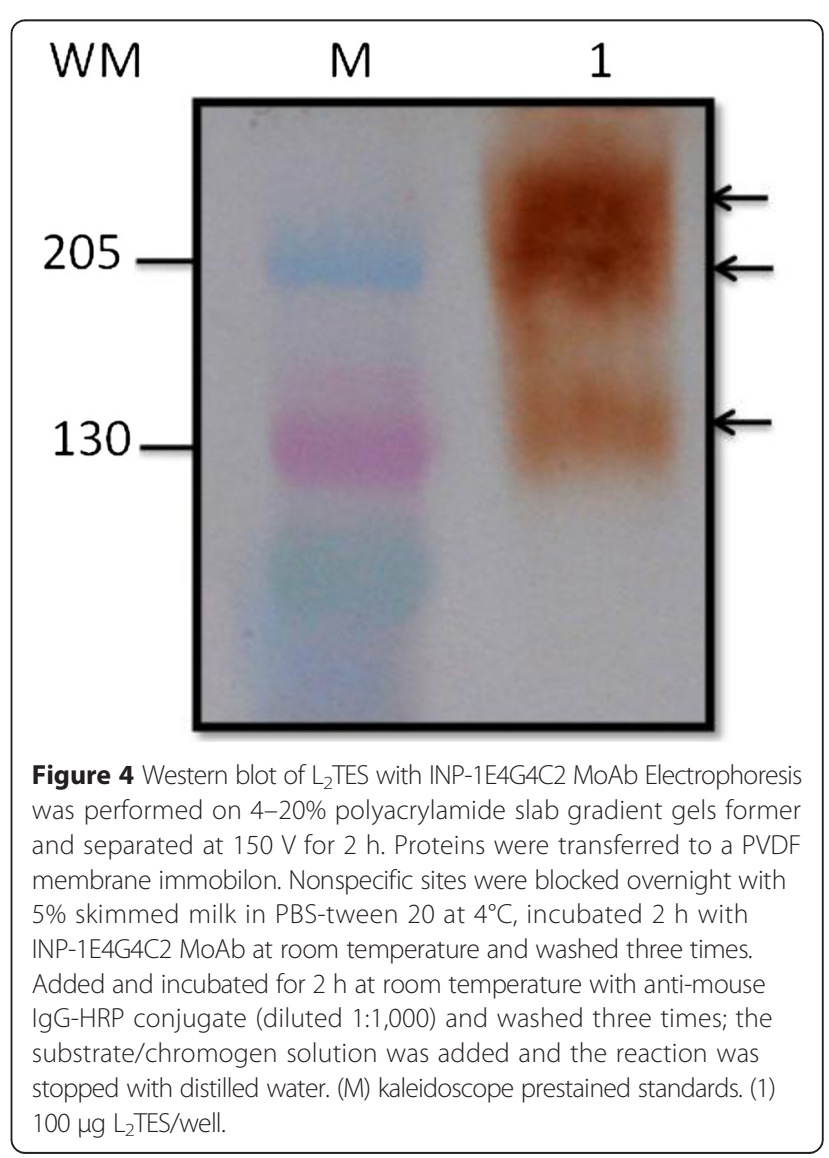


We used an approach of antigen capture by polyclonal antibodies instead of monoclonal, which gave higher analytical sensitivity $\left(440 \mathrm{pg} / \mathrm{mL}\right.$ of $\left.\mathrm{L}_{2} \mathrm{TES}\right)$ than those described by Yokoi and Ishiyama, who used MoAbs to coat the plate and were able to capture antigen from $4.0 \mathrm{ng} / \mathrm{mL}$ and $5.0 \mathrm{ng} / \mathrm{mL}$, respectively $[14,15]$.

It has been suggested that several monoclonal antibodies can detect more than one band and that recognize more than one epitope [15]. The INP-1E4G4C2 MoAb detected three bands of $\mathrm{L}_{2} \mathrm{TES}$, perhaps the capture of $\mathrm{pg} / \mathrm{mL}$ quantities of $\mathrm{L}_{2}$ TES was possible because the MoAb recognized several proteins which share epitopes. Yokoi [14] obtained a monoclonal antibody (IgG1) that did not cross-react with three parasites analyzed (A. suum, D. immitis and T. canis adult). Another study reported two monoclonal antibodies: one (IgM) that only identified T. canis excretion-secretion antigens, and other (IgG1) that distinguish $T$. canis and $T$. cati excretion-secretion antigens [13].

When we tested the method using antibody-positive samples, as defined by a commercial kit, we found circulating antigens in $31.0 \%$ of serum samples and none among 58 negative samples. These data suggest that 9 children had circulating antigens and perhaps larvae migration. It is likely that another 20 cases had antibodies against Toxocara from past infections, although it cannot be ruled out that they were individuals harboring other parasites, because the ELISA kit is unable to distinguish past infections from active infection and gives cross-reactions. Based on these data, we believe that the INP-1E4G4C2 MoAb could serve as a useful tool to demonstrate the presence of $\mathrm{L}_{2}$ T.canis circulating antigens, and therefore, to establish the infection status of the host. Moreover, we considered it is necessary to test the sandwich ELISA in more samples from patients.

\section{Conclusions}

With these tools we established a detection threshold as low as $440 \mathrm{pg} / \mathrm{mL}$ antigen. Monoclonal antibody is specific, and did not cross-react with antigens from other parasites. Detection of circulating antigens helps provide appropriate and timely treatment and prevents irreversible damage.

\footnotetext{
Abbreviations

ATES: Secretion excretion antigens from Toxocara canis adult; $\mathrm{Cl}$ : Confidence interval; CT: Covert toxocariasis; EDTA: Ethylenediaminetetraacetic acid; ELISA: Enzyme-Linked ImmunoSorbent Assay; EME: Eosinophilic meningoencephalitis; $\mathrm{H}_{2} \mathrm{O}_{2}$ : Hydrogen peroxide; $\mathrm{H}_{2} \mathrm{SO}_{4}$ : Sulfuric acid; IgG-HRP: Horseradish peroxidase conjugated IgG; INP-1E4G4C2 MoAc: Monoclonal antibody produced in Instituto Nacional de Pediatría clone 1E4G4C2; L ${ }_{2}$ T.canis: larvae 2 of Toxocara canis; $L_{2}$ TES: Larvae 2 Toxocara excretion-secretion antigens; MoAb: Monoclonal antibody; NaCl: Sodium chloride; NaCl Tween 20: Solution of sodium chloride with tween 20; OLM: Ocular larva migrans; PBS: Phosphate buffer solution; PBS-Tween 20: Phosphate buffer solution with tween 20; PoAb: Polyclonal antibodies; PVDF: Polyvinylidene difluoride; RPMI-1640: Roswell Park Memorial Institute medium 1640; SGHP: Medium of Saline, Glucose, Human Plasma; Tween 20: Polyoxyethylene Sorbitan Monolaurate; VLM: Visceral larva migrans.
}

\section{Competing interests}

The authors declare that they have no competing interests.

\section{Authors' contributions}

ARC conceived the study, samples collection, performed the experiments, analyzed the data and drafted the manuscript; YMF, MEME, AML were involved in the production of monoclonal and polyclonal antibodies; DC, SCS participated in study implementation and manuscript revision; MNMG, MPM conceived and designed the study, analyzed the data and wrote the manuscript. All authors read and approved the final version of the manuscript.

\section{Acknowledgements}

This work was supported in part by federal funds of Instituto Nacional de Pediatría (protocol 10/032), and federal founds of monoclonal antibody laboratory and rapid test laboratory of Instituto de Diagnóstico y Referencia Epidemiológicos.

\section{Author details}

${ }^{1}$ Laboratorio de Parasitología Experimental, Instituto Nacional de Pediatría, Insurgentes Sur No. 3700-C, Colonia Insurgentes Cuicuilco. Delegación Coyoacan, México D.F 04530, México. ${ }^{2}$ Laboratorio de Anticuerpos Monoclonales, Instituto de Diagnóstico y Referencia Epidemiológicos, Calle Francisco P Miranda No. 177. Col. Unidad Lomas de Plateros, Delegación Álvaro Obregón, México D.F 01480, México. ${ }^{3}$ Laboratorio de Pruebas Rápidas, Instituto de Diagnóstico y Referencia Epidemiológicos, Calle Francisco P Miranda No. 177. Col. Unidad Lomas de Plateros, Delegación Álvaro Obregón, México D.F 01480, México. ${ }^{4}$ Laboratorio de Inmunología Experimental, Instituto Nacional de Pediatría, Insurgentes Sur No. 3700-C, Colonia Insurgentes Cuicuilco. Delegación Coyoacan, México D.F 04530, México.

Received: 5 February 2015 Accepted: 24 April 2015

Published online: 08 May 2015

\section{References}

1. Despommier D. Toxocariasis: clinical aspects, epidemiology, medical ecology, and molecular aspects. Clin Microbiol Rev. 2003;16(2):265-72.

2. Schantz PM, Biagi FF. Coexistence of Toxocara and Toxascaris in dogs in Mexico city. J Parasitol. 1968;54(1):185-6.

3. Ponce-Macotela M, Peralta-Abarca GE, Martínez-Gordillo MN. Giardia intestinalis and other zoonotic parasites: prevalence in adult dogs from the southern part of Mexico city. Vet Parasitol. 2005;113(1-2):1-4.

4. Rodríguez-Caballero A, Luna-Ochoa Rl, Ponce-Macotela M, Peralta-Abarca GE, Martínez-Gordillo MN. A simple and inexpensive in vitro method for retrieving fertilized Toxocara canis eggs. Parasitol Res. 2007;101(3):829-32.

5. Traversa D. Pet roundworms and hookworms: a continuing need for global worming. Parasit Vectors. 2012;5(91):1-19.

6. Akuthota P, Weller PF. Eosinophilic pneumonias. Clin Microbiol Rev. 2012;25(4):649-60.

7. Schantz PM, Weis PE, Pollard ZF, White MC. Risk factors for toxocaral ocular larva migrans: a case control study. Am J Pub Health. 1980;70(12):1269-72.

8. Vidal JE, Sztajnbok J, Seguro AC. Eosinophilic meningoencephalitis due to Toxocara canis: case report and review of the literature. Am J Trop Med Hyg. 2003;69(3):341-3.

9. Nathwani D, Laing RB, Currie PF. Covert toxocariasis -a cause of recurrent abdominal pain in childhood. Br J Clin Pract. 1992;46(4):271.

10. Jacquier $P$, Gottstein $B$, Stingelin $Y$, Eckert J. Immunodiagnosis of toxocariosis in humans: evaluation of a new enzyme-linked immunosorbent assay kit. J Clin Microbiol. 1991;29(9):1831-5.

11. Muñoz-Guzmán MA, Del Río-Navarro BE, Valdivia-Anda G, Alba-Hurtado F. The increase in seroprevalence to Toxocara canis in asthmatic children is related to cross-reaction with Ascaris suum antigens. Allergol Immunopathol. 2010;38(3):115-21.

12. Romero Núñez C, Mendoza Martínez GD, Yañez Arteaga S, Ponce Macotela M, Bustamante Montes P, Ramírez Durán N. Prevalence and risk factors associated with Toxocara canis infection in children. ScientificWorldJournal. 2013;9(2013):572089. doi: 1155/2013/572089.

13. Robertson BD, Burkot TR, Gillespie SH, Kennedy MW, Wambai Z, Maizels RM. Detection of circulating parasite antigen and specific antibody in Toxocara canis infections. Clin Exp Immunol. 1988;74(2):236-41. 
14. Yokoi K, Kobayashi F, Sakai J, Usui M, Tsuji M. Sandwich ELISA detection of excretory secretory antigens of Toxocara canis larvae using a specific monoclonal antibody. Southeast Asian J Trop Med Public Health. 2002;33(1):33-7.

15. Ishiyamna S, Ono K, Rai SK, Uga S. Method for detecting circulating Toxocara canis antigen and its application in human serum samples. Nepal Med Coll J. 2009;11(1):9-13.

16. Ponce-Macotela M, Rodríguez-Caballero A, Peralta-Abarca GE, Martínez-Gordillo MN. A simplified method for hatching and isolating Toxocara canis larvae to facilitate excretory-secretory antigen collection in vitro. Vet Parasitol. 2011;175(3-4):382-5.

17. Bradford MM. A rapid and sensitive method for the quantitation of microgram quantities of protein utilizing the principle of protein-dye binding. Anal Biochem. 1976;72(7):248-54.

18. Köhler G, Milstein C. Continuous cultures of fused cells secreting antibody of predefined specificity. Nature. 1975;256(5517):495-7.

19. Galfrè G, Milstein C. Preparation of monoclonal antibodies: strategies and procedures. Methods Enzymol. 1981;73(Pt B):3-46.

20. Bowman DD, Mika-Grieve M, Grieve RB. Circulating excretory-secretory antigen levels and specific antibody responses in mice infected with Toxocara canis. Am J Trop Med Hyg. 1987;36(1):75-82

21. Gillespie H, Bidwell D, Voller A, Robertson BD, Maizels RM. Diagnosis of human toxocariasis by antigen capture enzyme linked immunosorbent assay. J Clin Pathol. 1993:46(86):551-4.

\section{Submit your next manuscript to BioMed Central and take full advantage of:}

- Convenient online submission

- Thorough peer review

- No space constraints or color figure charges

- Immediate publication on acceptance

- Inclusion in PubMed, CAS, Scopus and Google Scholar

- Research which is freely available for redistribution 